\title{
6
}

\section{'I NO LONGER HAVE A HOPE OF STUDYING'}

\section{Gender norms, education and wellbeing of refugee girls in Rwanda}

\section{Roberte Isimbi, Marie Merci Mwali, Ernest Ngabo and Ernestina Coast}

\section{Introduction}

Children and adolescents constitute the majority of refugees globally, and they have specific needs and vulnerabilities relative to the broader refugee population. Adolescence (10-19 years) represents a critical transition period - physically, psychologically and cognitively - in the second decade of life. We know relatively little about the lives of adolescent refugees, however, and how the intersections of age, gender and refugee status are influenced by social norms. Social norms are the informal rules or shared expectations in society, which carry incentives for compliance and penalties for transgression. Social norms shape understanding, beliefs, attitudes and behaviours in every context and include both descriptive norms (what people believe that other people in their context do) and injunctive norms (what people believe others should do) (Bicchieri, 2016). Gender norms - a shared understanding of how girls, boys, women and men should behave - are part of social norms (Crawford and Ostrom, 1995; Munoz-Boudet et al., 2013; Pulerwitz et al., 2019). For example, gender norms shape the information, support and services that adolescents have access to, their health status, the beliefs they hold and their (lack of) choice about when they have sex and with whom, including their ability to negotiate safer sex (Sommer and Mmari, 2015; Jones et al., 2016; Harper et al., 2017; Knopf et al., 2017; Berhane et al., 2019; Jones et al., 2019).

Focusing on adolescent Congolese refugees living in camps in Rwanda, this chapter uses a framework (GAGE consortium, 2019) that explicitly links a socioecological model that locates adolescents within their context, and incorporates adolescents' multidimensional capabilities. Socio-ecological approaches to understanding camp-based settings are rare (Williams et al., 2018), and demand acknowledgement that camps are highly specific spaces - economically, politically, socio-culturally - with power structures within and between camp residents and 
authorities. Camps are 'exceptional spaces' (Turner, 2016). This chapter focuses on how gender norms affect the well-being of, and opportunities open to, adolescent girls - including those who became mothers as adolescents - living in Rwanda's refugee camps. It focuses on two key capability domains: education and learning, and psychosocial well-being.

\section{Refugees in Rwanda}

Congolese refugees have been hosted in Rwanda since 1996, with a second wave arriving post-2011 (United Nations High Commissioner for Refugees (UNHCR), n.d.). It is estimated that there are 75,000 Congolese refugees in Rwanda. Refugees from the Democratic Republic of Congo (DRC) have fled persistent insecurity and ethnic conflict, and those in Rwanda mainly originate from the eastern provinces of North and South Kivu (International Refugee Rights Initiative (IRRI), 2011). This displacement has been protracted because of persistent and deep insecurity in the Kivu provinces and the presence of armed - at times, internationalised - groups in these areas. Congolese refugees in Rwanda express deep desires to return home, but fear the ongoing political and military insecurity (ibid.). The protracted displacement means that many refugees were born in Rwanda, and many experience childhood and adolescence in a camp-based setting; about half of the Congolese refugees in Rwanda are under 18 years of age.

The Rwandan Ministry of Emergency Management (MINEMA) and UNHCR are responsible for refugees' wellbeing. Most Congolese refugees in Rwanda live in high-density camps; all camps have health centres and some also have primary and/ or secondary schools, although some refugees attend schools outside the camps. Rwanda's policy approach to hosting refugees is focused on a camp-based model; it is estimated that in addition to the 75,000 camp-based refugees, there are around 1,100 urban-based Congolese refugees in the country. There is increasing concentration of Rwanda's refugee population in camps - rather than urban areas because of it being increasingly difficult for refugees to live in urban areas because of Rwanda's policy approach (MINEMA, 2019; UNHCR, 2019).

Refugees are included in Rwanda's broad definition of vulnerable groups. The 2005 Social Protection Policy covers orphaned children, prisoners' families, youth (aged 16-25), destitute people, refugees and returnees, and historically marginalised groups such as the Batwa (Kamurase et al., 2012). Article 18 of the 2014 Law Relating to Refugees stipulates that 'any person having obtained refugee status in Rwanda shall enjoy the rights and liberties provided for by international instruments on refugees ratified by Rwanda'. As a result, refugees are not mentioned explicitly in Rwandan national policy and legal instruments covering gender, children's rights, and education. The cross-sectoral National Integrated Child Rights Policy complies with the United Nations Convention on the Rights of the Child (UNCRC) and is aligned with international agendas such as the Sustainable Development Goals (SDGs) and Agenda 2030's call to leave no one behind. That principle underpins the SDGs and Agenda 2030, to be achieved by the 'unifying roadmap' 
(Boerma et al., 2020) of the United Nations' Every Woman Every Child (EWEC) global strategy (United Nations Secretary-General, 2015). The leave no one behind agenda is underpinned by a normative assumption of more inclusive development. However, this normative assumption requires us to identify who is being left behind and how to intervene to help them catch up - which, in turn, demands disaggregated data to illuminate inequities (Boerma et al., 2020; Requejo et al., 2020; Dawson, 2018). Responding to the SDGs' agenda, Rwanda has strengthened its emphasis on vulnerable populations in order to leave no one behind; however, we know little about how gender norms operate in refugee camps and host communities, and with what consequences for refugee adolescents.

The Global Compact on Refugees (2018) is a framework focused on sustainable solutions to refugee situations with four key objectives: (1) ease the pressure on host countries, (2) enhance refugee self-reliance, (3) expand access to thirdcountry solutions and (4) support conditions in origin countries for safe and dignified return. Whilst the Compact incorporates the need for longer-term responses, the emphasis on refugee self-reliance requires an enabling policy context that takes account of refugee heterogeneity. For example, if policies mean that some refugees - such as adolescent mothers - are excluded from opportunities to support their (and their children's) livelihoods, then the objective of self-reliance becomes far less achievable. The Compact frames refugees in a positive way - seeing refugees as an opportunity rather than a challenge for host countries; it also echoes the core commitment of the 2030 Agenda and the World Humanitarian Summit to leave no one behind. The Compact also highlights adolescents' vulnerabilities - and, to a much greater extent, girls' vulnerabilities. Its framing with respect to gender is highly focused around sexual and gender-based violence, and sexual exploitation and abuse; broader sexual and reproductive rights and health do not appear in the final version of the Compact (although they did appear in the earlier New York declaration) (Hennebry and Petrozziello, 2019).

Rwanda signed up to UNHCR's Comprehensive Refugee Response Framework (CRRF) in 2018, following four pledges the country made in 2016, shortly after the Framework's original launch. These pledges are: (1) to promote refugees' inclusion through a joint livelihoods strategy with UNHCR, (2) to provide all refugees with national identity (ID) cards and convention travel documents, (3) to give all urban refugees access to buy national health insurance and (4) to integrate 35,000 secondary school-age and 18,000 primary school-age refugee children into the national education system (Crawford et al., 2019).

These four pledges are reflected in Rwanda's Strategic Plan for Refugee Inclusion (2019-2024). Commitments to the CRRF have led to the issuing of ID cards to refugees - considered a major step in reducing the barriers to becoming 'self reliant members of Rwandan society who contribute to the economic development of their host districts' (Ministry of Disaster Management and Refugee Affairs (MIDIMAR) and UNHCR, 2016). However, the camp-based model of refugee hosting has been identified as being potentially at odds with the Global Compact's positive framing of refugees because it reinforces structural barriers (economic, 
geographic and educational) to opportunities for refugees (Crawford et al., 2019). Many Congolese refugees feel that Rwandan nationals treat them as outsiders and exclude them from socioeconomic participation and opportunities (IRRI, 2011). Rwanda's camp-based model reinforces barriers to economic inclusion with consequences that will differ for refugee sub-populations, including female adolescents who are mothers.

Underfunding has severely affected UNHCR operations in Rwanda, even though it continues to host increasing numbers of refugees. A review of funding for the CRRF in Rwanda suggests that 'there does not appear to be an unusual amount of energy being expended by government, donors or aid agencies to advocate for, or raise, additional development resources', and it notes that the funding situation is 'typical' of relatively stable settings with long-term displacement, which have 'perennial shortfalls' (Crawford et al., 2019).

Analysis of laws and policies on refugees in Rwanda reveals silences about how age and gender intersect to determine adolescents' opportunities and wellbeing. Articles 18 and 20 of the Law Relating to Refugees (2014) identify the rights of refugees provided for by international instruments and the rights to marriage, respectively, but do not mention age- or gender-specific needs or vulnerabilities. The Rwanda-UNHCR Livelihoods Strategy (2016-2020) is similarly silent, except for reference to unconditional cash for women to buy menstrual hygiene materials.

\section{Adolescent refugees in Rwanda: gender dimensions}

Historically, the significant body of literature on the vulnerability of forced migrants has attended to gendered rather than aged experiences. Extant research on refugees in Rwanda can be grouped into three broad foci. The first considers broader issues of durable solutions (voluntary repatriation, local integration, resettlement) for refugees (Easton-Calabria and Lindsay, 2013; Frydenlund, 2015) or adult women, with a specific focus on health (Pavlish, 2004, 2005). The second considers gendered differences in experiences of becoming and being a refugee in Rwanda (Pavlish and Ho, 2009; Ho and Pavlish, 2011; Bilgili et al., 2017). The final group has a predominantly biomedical focus on mental health of refugees, including adolescents (Mels et al., 2009, 2010), and intersections with violence against women (Sipsma et al., 2015; Wako et al., 2015) and against adolescent girls (Iyakaremye and Mukagatare, 2016; Meyer et al., 2017; Bermudez et al., 2018). For example, a study of the problems reported by Congolese adult refugees in a Rwandan camp showed that worrying about their adolescent daughters was a major parental concern (Pavlish, 2007). Another study found that girls alone in the house and in the camp at night face the risk of gender-based violence and abuse, and survivors do not use or are unaware of existing support or justice services (World Food Programme (WFP) and UNHCR, 2014). Interviews with refugee camp workers have drawn attention to the specific needs - including psychosocial needs - of some refugee sub-groups, particularly girls and women (Crawford et al., 2019). 
Compared to adult refugees, there is much less evidence on the impacts of adolescent refugees' broader experiences and lives in Rwanda (Alloush et al., 2017; Loschmann et al., 2019), with two notable exceptions. Williams et al.s (2018) work explores the risks of gender-based violence and sexual exploitation for camp-based adolescent girls in Rwanda. Focus group discussions (FGDs) held with adolescent boys and girls and their parents and caregivers highlighted how the camp setting generated new forms of vulnerability - economic and sexual - that were highly gendered. The authors highlight the need for an intersectional approach to understanding adolescents' vulnerabilities, situated within a socio-ecological understanding of the camp setting. Ruzibiza's (2020) work draws attention to the stigma experienced by Burundian adolescent refugees who are either pregnant or have started childbearing in a refugee camp setting in Rwanda. Drawing on ethnographic evidence from unmarried adolescents aged 13-19 years, Ruzibiza shows how despite an enabling policy environment that supports pregnant adolescents to remain in education, the stigma of early and non-marital pregnancy and childbearing leads to high levels of school dropout.

With the exception of Ruzibiza's work on Burundian refugees, there is very little evidence relating specifically to the experiences of refugee adolescent mothers in Rwanda, and the broader gendered experiences of refugee adolescents with reference to education and psychosocial wellbeing. Evidence tends to be in the grey literature and is more descriptive and focused on intervention evaluation (often with weak research designs). In addition, this evidence tends to ignore the intersections of gender, age, refugee status and motherhood and instead uses broader aggregated groupings of child/adult or male/female. An assessment conducted in four camps found that refugees resort to negative coping strategies to deal with poverty or food shortages, including underfeeding, theft/robbery, high-risk casual labour and transactional sex (WFP and UNHCR, 2014). There are schools providing nine years of basic education in camps, although school dropout is attributed to a combination of limited parental interest in child education and overcrowded classrooms (especially for older students having to retake failed classes with younger students). Girls face specific problems stemming from a lack of separate toilets with access to water and that afford privacy. A school feeding programme for refugee students is reported to have reduced dropout and increased attendance and completion, particularly for girls; however, in some refugee camps, families had to pay a monthly 'voluntary' contribution to community workers involved in school feeding (WFP and UNHCR, 2014). Apart from men and women, adolescent girls and boys are also involved in food management through their elected representatives (WFP, 2018).A study in Kiziba camp mentions the existence of clubs and committees for adolescent refugees (UNHCR, 2014.

The limited evidence points to the need for an approach to situating and understanding the experiences, capabilities and needs of refugees that takes into account not only gender and age but also parenthood. By focusing on refugee female adolescents who are mothers, we consider how individual capabilities and contexts 
(family/household, social norms, structural barriers) shape individual outcomes. For example, one study showed that refugee girls are at high risk of school dropout due to pregnancy, with linkages to social pressures to engage in transactional sex with men in exchange for money or goods. Refugee adolescents who seek employment as domestic workers in Kigali may become pregnant, with a range of outcomes: some may be rejected and chased out of the house by their families, while others return to work to Kigali post-birth and send money to their mother, who looks after their baby in the refugee camp (Pavlish, 2007).

There is limited quantitative data on adolescent refugees in Rwanda, but that which is available also underlines the challenges they face. In a UNHCR study, 27 per cent of adolescents in Kiziba camp reported high anxiety symptoms, 72 per cent witnessed shouting and yelling at home, 18 per cent had seen physical violence at home and 20 per cent reported feeling unsafe in their home (UNHCR, 2014). Meyer et al.s (2017) latent class analysis of adolescents' exposure to violence and psychosocial outcomes in refugee camps in Uganda and Rwanda finds that Congolese adolescents in Kibiza camp in Rwanda have significantly higher exposure to violence than refugees in Uganda, which they attribute to the protracted nature of their displacement. It is important here to emphasize the need to read these findings on violence in relation to the specific conglomeration of traumatic experiences, uncertain futures and daily economic challenges facing refugee communities in Rwanda, which creates an environment of extreme stress that adolescent girls must navigate. These findings do, however, indicate the need for support that reflects differential patterning of mental health concerns in particular contexts, given these pressures.

\section{Methods}

Adaptations of the GAGE methodological toolkit were used, to reflect the focus of our research on refugee populations and two capability areas (education and learning, psychosocial well-being). Tools used included: in-depth interviews (IDIs) with adolescents, IDIs with caregivers, key informant interviews, FGDs and a life history interview developed specifically for adolescent mothers (Table 6.1).

In-depth life history interviews were conducted with adolescent mothers, defined as those who were aged below 25 years and had given birth before age 19 . Adolescent mothers were identified for inclusion in the study through purposive snowballing, though this proved extremely difficult due to the stigma attached to adolescent motherhood. For example, girls were hidden by their families and their babies 'claimed' by grandmothers as their own (including cases where adolescent mothers are in paid employment outside the camp). The challenges of recruiting adolescent mothers to this study only serve to underscore how stigma and gendered norms about adolescent childbearing intersect to influence adolescent refugees' lives.

Primary evidence was generated from three Rwandan refugee camps (Table 6.2), purposively selected as long-established camps, meaning that adolescents 
TABLE 6.1 Research methods and sample sizes

\begin{tabular}{lll}
\hline Research method & Population & $n$ \\
\hline In-depth & Female adolescents aged 10-12 & 36 \\
interviews (IDI) & Caregivers of female adolescents aged & 37 \\
& $\quad$ 10-12 & \\
& Male adolescents aged 10-12 & 31 \\
& Caregivers of male adolescents aged 10-12 & 31 \\
& Female adolescents aged 13-15 & 33 \\
& Male adolescents aged 13-15 & 32 \\
& Adolescent mothers & 12 \\
Focus group & Key informants: opinion leaders and service & 20 \\
discussion & providers & \\
(FGD) & Female adolescents aged 10-15 & 1 FGD (8 participants) \\
& Adult female caregivers & 1 FGD (8 participants) \\
& Adult male caregivers & 1 FGD (4 participants) \\
\hline
\end{tabular}

${ }^{\star}$ Adolescents who had given birth before age 20 .

TABLE 6.2 Study site locations and characteristics

\begin{tabular}{|c|c|c|c|c|c|c|}
\hline \multirow[t]{2}{*}{ Camp } & \multirow{2}{*}{$\begin{array}{l}\text { Year } \\
\text { established }\end{array}$} & \multicolumn{2}{|l|}{ Location } & \multicolumn{2}{|c|}{ Population } & \multirow{2}{*}{$\begin{array}{l}\text { Source of income (other } \\
\text { than food assistance) }\end{array}$} \\
\hline & & District & Province & Female & Male & \\
\hline Gihembe & 1997 & Gicumbi & Northern & 7,148 & 6,156 & $\begin{array}{l}\text { Non-farm waged } \\
\text { work }\end{array}$ \\
\hline Nyabiheke & 2005 & Gatsibo & Eastern & 7,959 & 6,595 & $\begin{array}{l}\text { Camp-based small } \\
\text { businesses (e.g. } \\
\text { retail shop) }\end{array}$ \\
\hline Kigeme & 2012 & Nyamagabe & Southern & 11,179 & 9,139 & $\begin{array}{l}\text { Small businesses (e.g. } \\
\text { selling foodstuffs) }\end{array}$ \\
\hline
\end{tabular}

participating in the research were either born in Rwanda or had arrived there from DRC at a very young age.

The fieldwork was conducted by a team of young Rwandans, four women and four men, all university educated, and all with extensive training and experience in qualitative research, including refugee-specific training. Prior to data collection (2018) the study received ethical approval from the Rwanda National Ethics Committee. For legal minors (those under 18 years), informed consent was sought from a guardian in addition to assent from the minor. The Ministry of Emergency Management (MINEMA) (formerly MIDIMAR) granted authorisation to access the refugee camps and provided letters of access for the camp authorities.

The analyses here use the Gender and Adolescence: Global Evidence (GAGE) conceptual framework, which reflects the close connections between '3 Cs': 
capabilities, change strategies and contexts (GAGE consortium, 2019). ${ }^{1}$ Adolescents are situated at the centre of this socio-ecological framework, which encompasses the deeply gendered processes by which adolescents acquire key capabilities during this life stage and how these capabilities are affected by gender, pregnancy and motherhood before the age of 18. We developed a thematic codebook informed by our conceptual framework, inviting comments from researchers involved in the fieldwork to sense-check codes and add nuance. FGDs and interviews were recorded and transcribed directly into English by research assistants. Coding was done using MAXQDA qualitative data analysis software.

\section{Results}

We structure our results by first considering how gendered norms manifest in and have an impact on the lives of refugee adolescent boys and girls focusing on two capabilities: education and learning, and psychosocial wellbeing. These capability domains were selected following a review of secondary evidence, which suggested that adolescent refugees were more likely to experience negative outcomes in these domains than their non-refugee peers. Our analyses show that the gendered nature and implications of adolescent labour - specifically time-consuming care work was most salient for our respondents, boys and girls, mothers and non-mothers. Next, we consider more fully the implications of these gendered norms for adolescents who have become mothers and the consequences for their lives across the two capability domains.

\section{Gender and care work}

Household labour is highly gendered. Work associated with caring (cooking, taking food to the hospital when there is someone sick in the family, fetching water, taking care of younger siblings, sweeping, washing dishes, washing clothes, collecting firewood and plastering the walls) is done by girls; work considered to be physically demanding is assigned to boys. Girls' caring tasks were sometimes assigned to boys, but only if a girl was unavailable, and boys noted that they were rewarded for doing girls' tasks in ways that girls were not:

I fetched water, washed dishes and swept the house and my mother rewarded me.

(IDI with adolescent boy, 13-15 years, Gihembe camp)

Adolescents internalised these gendered divisions of labour, and girls felt that caring tasks were harder for boys to do. The critical difference in the consequences of this division of labour is that girls' caring tasks consume much more of their time than do the tasks allocated to boys; girls' tasks are many and constant. Adolescent girls drew a connection between their tasks and their lesser availability for, and performance in, school work; boys were alert to this implication: 
She cannot find any single time to revise her lessons, her mum is disabled, she is the one to cook, to wash dishes, while her dad has gone to the bar, as a Primary 6 student, she has no time to prepare herself for final exams.

(Participant in FGD of a vignette, adolescent boys, 10-12 years, Kigeme camp)

Girls' time-consuming care burden was also reflected in reduced time for leisure, which was identified by both boys and girls as an important aspect of their lives:

[Male adolescents] do nothing at home except playing football every day or running on the street while girls are doing domestic work.

(IDI with father of adolescent boy, Nyabiheke camp)

Adolescent refugee girls' time is much more constrained and occupied compared to their male peers, with implications for education, leisure and playing. One particular outcome linked to education was the way in which time-consuming care work meant that girls were more exposed to the risk of corporal punishment at school if they arrived late. In this way, the capability outcome on education and learning is directly impacted by gendered norms around the household division of labour. Experience of school-based violence perpetrated by teachers was another reported cause of school dropout:

What made me sad is that my teacher beat me hard. She stepped on me with her long shoes and my nail was removed. As I was hurt, my mother decided to get me out of the school and I spent a whole year without studying.

(IDI with adolescent girl, 10-12 years, Gihembe camp)

\section{Adolescent mothers}

Non-marital childbearing by adolescent girls is highly stigmatised and has profound consequences for refugee adolescent mothers, throughout their lives and across multiple domains. Our analyses focus on education and learning and psychosocial wellbeing. The impacts of adolescent childbearing on education and learning, and on psychosocial wellbeing, are interlinked. Strongly gendered norms of responsibility and blame for pregnancy outside marriage mean that girls are highly stigmatised for being pregnant; they are sanctioned for the visible evidence of their unacceptable non-marital sexual activity:

My mother told me to go back to the person who impregnated me.... I couldn't stay at home and I couldn't even go back to the man.

(Life history interview with adolescent girl who gave birth at age 18, Kigeme camp)

\section{Education and learning}

Despite legal and policy frameworks in Rwanda that are supportive of pregnant girls remaining in school, and returning to school post-birth, the reality for the 
adolescents we interviewed is that both these options were either impossible or very difficult and dependent on familial support:

I stopped going to school when I knew I was pregnant. I was not expelled. Instead I am the one who dropped out because I didn't want people to know that I was pregnant.

(Life history interview with adolescent girl who gave birth at age 17, Nyabiheke camp)

For others, becoming pregnant was the stimulus for seeking non-camp-based work, in order to provide for their baby:

I decided to drop out of school when I knew I was pregnant and went to work at Kigali to look for a job to be able to prepare for the child because I knew that no one would help me, and the [man] responsible had denied the pregnancy.

(Life history interview with adolescent girl who gave birth at age 17, Nyabiheke camp)

For one respondent, her relative poverty within the refugee camp was a source of profound stigma, which - reflecting the very limited economic opportunities available to her in a camp setting - led to her leaving the camp to find work:

I lacked shoes, my clothes were old, and I saw that I have no other option, I had started being embarrassed in front of other children and I decided to go. No one was aware, I did not tell anyone that I am leaving; and I went, arriving there, I immediately found a job, and it is in this job (domestic work) where I got pregnant.

(Life history interview with adolescent girl who gave birth at age 18, Kigeme camp)

Adolescent mothers who had left the camp to seek economic opportunities - often for domestic work in urban areas (one of very few jobs they were skilled to do) reported being exposed to work-based sexual harassment:

I dropped school and went to look for a job to be able to buy everything I needed like shirts and other clothes. Arriving there (urban area), you could find men who were asking me for sex, I could refuse and leave that home to look for another place to work. I could be asked for sex in all homes I could arrive in. I got stressed where I first worked, and left. After getting work, life became worse, they treated me anyhow.

(Life history interview with adolescent girl who gave birth at age 17, Gihembe camp) 
All of the adolescent mothers we interviewed who had left the camp for economic opportunities had returned due to the pregnancy; our research design does not include adolescents who did not subsequently return to the camp - either when still pregnant or as a mother. The demands of childcare for adolescent mothers effectively curtailed any options of returning to education - unless alternative care could be found. While in some cases grandmothers might have been able to provide this care, it was not necessarily available:

I am not planning to go back to school. It is not in my plans. If I go back, who will I be leaving my child with? My mother cannot accept to care for him for me to go back to school. Maybe when he [the baby] grows up and starts going to school as well. . . Maybe then, we can go to school together but now, I have left school because I am raising him. When his time to start school comes, I will go back to school also.

(Life history interview with adolescent girl who gave birth at age 18, Kigeme camp)

Adolescent mothers aspire to return to school but see little opportunity to even raise this as an option, let alone achieve it. For many, becoming a mother permanently alters their future aspirations and impacts their psychosocial wellbeing, despite their young age:

Mum talks to me but she doesn't raise a conversation of going back to school. She is not happy with me, and my brother undermines me. When night comes, I feel sad, when it is towards $7 \mathrm{pm}$. Sometimes when I see them coming back in a bad mood, I become more careful and eating when you are in a doubting mood is also hard; so, I sleep without food and feed my child. So, I feel like the night should not be coming.

(Life history interview with adolescent female who gave birth at age 18, Kigeme camp)

Parents of adolescent mothers were identified as critical - mainly in terms of support for childcare, shelter and food - for their daughter's future trajectory. Where families did support an adolescent mother, then returning to school or earning an income became more of a possibility; where this support was withdrawn - often as a sanction for non-marital sex, pregnancy and childbearing - adolescent mothers rarely had any option but to fend for themselves. The stigma of non-marital childbearing for adolescents was multiple: from the family, at school, from the wider community and even the health services they needed to attend for their pregnancy, delivery and early childhood care. Adolescent mothers were critically aware of the need to provide for their child but also of how their curtailed education impacted their future economic opportunities:

Because of the responsibility of raising my child, it is not easy for me, my child needs to eat and dress. I no longer have a hope of studying. Instead, 
I think of how to care for his needs.... I wish I get a chance of doing a vocational course like mechanics to easily get a job and cater for my child's needs.

(Life history interview with adolescent girl who gave birth at age 16, Kigeme camp)

Adolescent mothers expressed sadness about their lost educational opportunities and were highly focused on the material needs of their child:

I used to be intelligent but today I feel like the cleverness has faded. Even if I go back to school I will keep thinking about my child, thinking of how to get a good shoe for my child, a good trouser, I always desire dressing my child smartly as I want to be smart too.

(Life history interview with adolescent girl who gave birth at age 16, Kigeme camp)

\section{Psychosocial wellbeing}

Adolescent mothers experience stressors to their psychosocial wellbeing, including rejection by their families, which they reported left them feeling depressed. If the pregnancy or baby was also rejected or denied by its father, this further strained the girl's psychosocial wellbeing. Adolescent childbearing means that onceclose maternal support is withdrawn because the girl has transgressed social norms around non-marital sexual activity and pregnancy. For one interviewee, she was able to gain support from an older sister when her mother withdrew her emotional and practical support:

She [mother] always told me that she had always told me to stay away from that neighbour [father of my child]. She would always remind me of it. When I came back, my older sister was the one to accept me; she alone would go with me to the health centre because I was shy to show up in public.

(Life history interview with adolescent girl who gave birth at age 16, Gihembe camp)

Adolescent mothers, rejected by their families and marginalised by their communities, reported excluding themselves from everyday life because of feelings of unworthiness. This is reflected in the language used by some adolescents to refer to themselves once they became mothers, including 'excrement' and 'not intelligent'. Respondents identified that pregnancy and motherhood brought additional burdens, including their reduced ability to provide food for themselves:

Ever since she [baby]was born, life keeps deteriorating because she requires a lot I don't have.

(Life history interview with adolescent girl who gave birth at age 16, Kigeme camp)

The camp-based situation of the adolescents we interviewed meant that some services were available, and occasionally, intervention by service providers appeared to influence the way pregnant girls were treated by their families: 
Before Plan International came, I was staying here with my big sister who has two children. Plan came and taught my family members to not give me hard work to do since I was pregnant. Plan still came to visit me and found that I had no mattress, they told mum to go and pick the mattress, the towel and the clothes for the baby. And I was very happy for that, thinking on how I was going to sleep without a mattress was a problem to me even though I was sleeping without before.

(Life history interview with adolescent girl who gave birth at age 14, Nyabiheke camp)

The highly stigmatised experiences reported by adolescent mothers were at odds with how some service providers perceived the issue:

A girl from 15 years to 18 years is considered ready enough for marriage. They take it in their culture, girls of 16 or 17 years old are taken for marriage. For them, seeing an adolescent girl pregnant is common and considered normal. . . Impregnating a girl of 15 years to 20 years is not seen as a problem.

(Key informant interview with service provider, Nyabiheke camp)

This key informant presented Congolese refugees (they) as different to Rwandans; assumptions about gendered norms of the Congolese community are perceived to be at odds with and distinct from the Rwandan legal context (where the minimum legal age of marriage is 21 years). This 'othering' of Congolese refugees also meant that camp service providers appeared to blame refugee communities for not seeking legal justice in cases where girls experienced sexual violence:

Rape cases exist but the reported ones are very few because of the silence and simplification culture in the camp. The refugees know there is a law in Rwanda that punishes those crimes and, instead of reporting, they reconcile. Their mindset is that rape is a common problem and [there is] no need to report. ... When a girl of 15-20 years gets pregnant, they think there is no problem. They take it as their culture accepts it. Also, when it happens and the father of the baby agrees to support the girl, they take it as a too simple problem to be reported.

(Key informant interview with service provider, Nyabiheke camp)

In Rwanda the stigma of adolescent pre-marital childbearing is not restricted to Congolese refugees; non-marital pregnancy and childbearing by Rwandan adolescents is similarly stigmatised and associated with school dropout (Coast et al., forthcoming).

\section{Discussion}

Our research findings are significant because they highlight the extreme vulnerability of some adolescent refugee girls and the lifelong implications of their 
experiences. Refugee adolescent mothers in particular are exceptionally vulnerable because of the stigma associated with non-marital pregnancy and childbearing. Our evidence underscores that within a population that is broadly defined as vulnerable (refugees), there are distinct categories of vulnerability that heighten the risk of being left behind. Adolescent refugee mothers are one such distinct group, and this finding reinforces the need for an approach to their needs that is grounded in the specific context of Rwanda's refugee camps. Despite Rwanda's commitment to the Global Compact on Refugees, adolescent refugee mothers are being left behind. They are invisible in official data - and their statistical invisibility only serves to leave them (and most probably their children) even further behind. The camp-based model of refugee hosting that the CRRF provides means that refugee adolescents are distant (geographically, socially, economically) from opportunities for self-reliance.

Our evidence demonstrates the need for very particular attention to be paid to the outcomes for refugee adolescent mothers; a combination of stigma and lack of dedicated services means that a pregnant and unmarried refugee girl is likely to experience significant negative impacts across her life course. These include - but are not limited to - poor psychosocial outcomes, higher poverty levels and lower education. There are also implications for her child or children (though this was not explored by our study). A recent Rwandan policy change on the provision of contraception to adolescents means that adolescent refugees being able to access effective contraceptive services could significantly reduce the number of unwanted and/or unplanned pregnancies. However, there are also established Rwandan policies and institutions that could be better used for and by refugees. For example, in 2015, the government established the technical and vocational education and training (TVET) policy; refugee adolescent mothers could potentially benefit from TVET for both educational and economic opportunities.

Our evidence and analyses highlight substantial disconnects between the legal, policy and cultural contexts. Under the Rwandan policy and legal framework, engaging in sexual activity with an adolescent under the age of 18 is a criminal offence (even if the sex is consensual between two adolescents). There are multiple consequences of this, including high rates of unsafe abortion (Basinga et al., 2012; Rulisa et al., 2015), lone motherhood and absent fatherhood (Coast et al., forthcoming). Even though many of the adolescent refugees we interviewed were born in Rwanda or spent most of their life in Rwanda, the cultural context of the DRC is one of child marriage. In DRC, the legal age of marriage is 18 years; however, in 2014, 13.8 per cent of Congolese women aged 25-49 years were married by age 15 (National Institute of Statistics of Rwanda, Ministry of Finance and Economic Planning/Rwanda, Ministry of Health/Rwanda, and ICF International, 2015). The dissonance between Congolese norms around marriage and adolescent childbearing and the Rwandan legal and policy setting is stark, and adolescent childbearing by Congolese refugees in Rwanda brings this dissonance into sharp focus. Adolescent refugees - many of whom were born in Rwanda - experience a critical conjunction: the child marriage and childbearing norms of their own parents versus a 
Rwandan social policy and legal system that does not (to a large extent) recognise or support adolescent childbearing, and makes marriage before age 21 illegal. This might, to some extent, explain the highly stigmatised nature of adolescent childbearing among the refugee population in Rwanda, reflected in the difficulties we experienced in recruiting adolescent mothers for this research.

The Comprehensive Sexuality Education curriculum developed by the United Nations Educational, Scientific and Cultural Organization (UNESCO) has recently been integrated into the Rwandan primary and secondary education curriculum, moving from knowledge-based to competence-based curriculum. This curriculum includes aspects on sexuality and how to avoid sexually transmitted illnesses as well as unwanted pregnancies by using condoms and other contraceptive methods. The adoption of this new curriculum has been accompanied by the establishment of 'youth corners' - a place for adolescents to access contraceptives confidentially in all health centres, including in refugee camps. Whilst at the time of our research, these youth corners had not been established in the camps, these spaces offer the opportunity for adolescent girls' sexual agency to be supported.

Taken together, these multiple intersecting contexts - legal, educational and cultural - pose a paradox. The education and service contexts mean that adolescent refugees are supposed to be educated about sexuality, and provided with contraceptive services, yet any sexual activity under the age of 18 is criminalised. When combined with the stigma of adolescent motherhood, adolescent refugee girls are highly vulnerable to the risks (physical and mental health risks, as well as economic and educational risks) and consequences of unplanned pregnancy. Our evidence shows that adolescent mothers do not exist in a capabilities deficit; they also show agency, in their maintenance of aspirations for a better future and active search for livelihood opportunities beyond the camp. However, this agency is constrained by a context that does not support their future aspirations for themselves and their children; the camp-based nature of Rwanda's CRRF serves to increase the structural barriers to livelihood self-reliance. This means that these ambitions of alternative livelihood opportunities may end in a return to a camp, and having to cope with the stigma of non-marital motherhood within their communities. More work is needed to explore how to deliver the support that is necessary for adolescent girls to reach their goals, whilst keeping in mind these structural constraints. Improving access to expanded TVET opportunities under current policy initiatives by the government, for example, would put emphasis on the need for better institutional support for the most vulnerable - rather than placing the blame for being 'left behind' upon girls and their communities.

\section{Conclusion}

Gendered norms have a profound impact on the lives of adolescent refugee girls who become mothers; evidence and analyses that ignore how gender, age, refugee status and motherhood intersect only serve to further stigmatise and render invisible this highly vulnerable group. A systematic review of sexual and reproductive 
health knowledge, experiences and access to services among refugee, migrant and displaced girls and young women in Africa reiterated the dearth of evidence relating to these populations and strengthened calls for evidence that is disaggregated at the very least - by age and sex (Ivanova et al., 2018). Our qualitative evidence shows that age and sex disaggregation alone is unlikely to achieve the aims of the leave no one behind agenda; refugee adolescent mothers continue to be left behind in their future trajectories, in camps and by laws and policies.

There are significant challenges, including the underfunding of UNHCR combined with growing demand for services for refugees. This resource-constrained context requires significant efforts to prevent adolescent refugees (and their children) being left behind. The Global Compact on Refugees acknowledges that refugees have more than immediate needs; adolescent refugees, and their children, need long-term solutions to dismantle the structural barriers to self-reliance. Prioritising integration as a durable solution for Congolese refugees in Rwanda is essential in the context of chronic volatility and ongoing political failures to maintain peace that continue to beleaguer the Democratic Republic of Congo.

Refugee adolescent mothers in Rwanda need social protection because of the impact of pregnancy on their family support networks. Despite a policy environment that ostensibly provides for pregnant adolescents to remain in school, stigma remains a significant barrier within Rwandan and Congolese communities alike. At the community level, investing in communications and messaging to support and include pregnant adolescents and adolescent mothers - rather than exclude them - could yield broad benefits for adolescent parents and their children by challenging this stigma. Educational opportunities (including vocational training) that accommodate their childcare needs could also start to dismantle this critical barrier to self-reliance. Moves by the Rwandan government to expand comprehensive sexuality education and broader efforts under the Global Compact to integrate Congolese adolescents into the Rwandan school system offer a route to support the agency of girls in navigating the social norms and economic challenges that constrain their capabilities during displacement.

\section{Notes}

1 GAGE consortium (2019) Gender and adolescence. Why understanding adolescent capabilities, change strategies and contexts matters. Second Edition. London: Gender and Adolescence: Global Evidence. https://www.gage.odi.org/publication/gage-conceptualframework-second-edition/

\section{References}

Alloush, M., Taylor, J. E., Gupta, A., Rojas Valdes, R. I., and Gonzalez-Estrada, E. (2017) Economic life in refugee camps. World Development 95: 334-347.

Basinga, P., Moore, A. M., Singh, S. D., Carlin, E. E., Birungi, F., and Ngabo, F. (2012) Abortion incidence and postabortion care in Rwanda. Studies in Family Planning 43(1): 11-20. 
Berhane,Y., Worku, A., Tewahido, D., Fasil, N., Gulema, H., Tadesse, A. W., and Abdelmenan, S. (2019) Adolescent girls' agency significantly correlates with favorable social norms in Ethiopia - implications for improving sexual and reproductive health of young adolescents. Journal of Adolescent Health 64(4): S52-S59.

Bermudez, L. G., Parks, L., Meyer, S. R., Muhorakeye, L., and Stark, L. (2018) Safety, trust, and disclosure: a qualitative examination of violence against refugee adolescents in Kiziba camp, Rwanda. Social Science \& Medicine 200: 83-91.

Bicchieri, C. (2016) Norms in the wild: how to diagnose, measure, and change social norms. Oxford: Oxford University Press.

Bilgili, Ö., Loschmann, C., and Siegel, M. (2017) The gender-based effects of displacement: the case of Congolese refugees in Rwanda. KNOMAD Working Paper 21. Global Knowledge Partnership on Migration and Development.

Boerma, T., Victora, C. G., Sabin, M. L., and Simpson, P. J. (2020) Reaching all women, children, and adolescents with essential health interventions by 2030. British Medical Journal 368: 16986.

Coast, E., Mwali, M. M., Isimbi, R., Ngabonzima, E., Pereznieto, P., Buzby, S., Dutton, R., and Baird, S. (forthcoming) Our children are fatherless: exploring experiences of adolescent pregnancy and motherhood in Rwanda. European Journal of Development Research.

Crawford, N., Holloway, K., and Lowe, C. (2019) The comprehensive refugee response framework: progress in Rwanda. HPG Working Paper 24. London: Overseas Development Institute, Humanitarian Policy Group.

Crawford, S. E., and Ostrom, E. (1995) A grammar of institutions. American Political Science Review 89(3): 582-600.

Dawson, N. M. (2018) Leaving no-one behind? Social inequalities and contrasting development impacts in rural Rwanda. Development Studies Research 5(1): 1-14.

Easton-Calabria, E., and Lindsay, A. (2013) Towards durable solutions for protracted Congolese refugees in Rwanda. Oxford Monitor of Forced Migration 3(2): 58-66.

Frydenlund, E. (2015) Home was Congo: refugees and durable displacement in the borderlands of 1,000 hills. Dissertation, Old Dominion University.

GAGE consortium. (2019) Gender and adolescence: why understanding adolescent capabilities, change strategies and contexts matters. Second edition. London: Gender and Adolescence: Global Evidence.

Harper, C., Jones, N., Marcus, R., Ghimire, A., and Kyomuhendo Bantebya, G. (2017) Empowering adolescent girls in developing countries: gender justice and norm change. Abingdon: Routledge.

Hennebry, J. L., and Petrozziello, A. J. (2019) Closing the gap? Gender and the global compacts for migration and refugees. International Migration 57(6): 115-138.

Ho, A., and Pavlish, C. (2011) Indivisibility of accountability and empowerment in tackling gender-based violence: lessons from a refugee camp in Rwanda. Journal of Refugee Studies 24(1): 88-109.

International Refugee Rights Initiative (IRRI). (2011) Shadows of return: the dilemmas of Congolese refugees in Rwanda. Citizenship and displacement in the Great Lakes Region. Working Paper 6. Kampala, Uganda: IRRI.

Ivanova, O., Rai, M., and Kemigisha, E. (2018) A systematic review of sexual and reproductive health knowledge, experiences and access to services among refugee, migrant and displaced girls and young women in Africa. International Journal of Environmental Research and Public Health 15(8): 1583.

Iyakaremye, I., and Mukagatare, C. (2016) Forced migration and sexual abuse: experience of Congolese adolescent girls in Kigeme refugee camp, Rwanda. Health Psychology Report 4(3): 261-271. 
Jones, N., Presler-Marshall, E., Baird, S., Hicks, J., Chuta, N., and Gezahegne, K. (2019) Adolescent health, nutrition, and sexual and reproductive health in Ethiopia. London: Gender and Adolescence: Global Evidence.

Jones, N., Tefera, B., Emirie, G., Gebre, B., Berhanu, K., Presler-Marshall, E., Walker, D., Gupta, T., and Plank, G. (2016) One size does not fit all: the patterning and drivers of child marriage in Ethiopia's hotspot districts. London: United Nations Children's Fund (UNICEF) and Overseas Development Institute.

Kamurase, A., Wylde, E., Hitimana, S., and Kitunzi, A. (2012) Rwanda: social safety net assessment. Social Protection Discussion Papers and Notes 91577. Washington, DC: The World Bank.

Knopf, A. S., McNealy, K. R., Al-Khattab, H., Carter-Harris, L., Oruche, U. M., Naanyu,V., and Draucker, C. B. (2017) Sexual learning among East African adolescents in the context of generalized HIV epidemics: a systematic qualitative meta-synthesis. PLOS ONE 12(3): $\mathrm{e} 0173225$.

Loschmann, C., Bilgili, Ö., and Siegel, M. (2019) Considering the benefits of hosting refugees: evidence of refugee camps influencing local labour market activity and economic welfare in Rwanda. IZA Journal of Development and Migration 9(1): 5.

Mels, C., Derluyn, I., Broekaert, E., and Rosseel,Y. (2009) Screening for traumatic exposure and posttraumatic stress symptoms in adolescents in the war-affected eastern Democratic Republic of Congo. Archives of Pediatrics \& Adolescent Medicine 163(6): 525-530.

Mels, C., Derluyn, I., Broekaert, E., and Rosseel, Y. (2010) The psychological impact of forced displacement and related risk factors on Eastern Congolese adolescents affected by war. Journal of Child Psychology and Psychiatry 51(10): 1096-1104.

Meyer, S., Yu, G., Hermosilla, S., and Stark, L. (2017) Latent class analysis of violence against adolescents and psychosocial outcomes in refugee settings in Uganda and Rwanda. Global Mental Health 4.

Ministry in Charge of Emergency Management (MINEMA). (2019) Strategic plan for refugee inclusion (2019-2024). Kigali: MINEMA.

Ministry of Disaster Management and Refugee Affairs (MIDIMAR) and UNHCR. (2016) Economic inclusion of refugees in Rwanda: a joint strategy by the Ministry of Disaster Management and Refugee Affairs and the United Nations High Commissioner for Refugees for furthering economic development in host communities through refugee self-reliance (2016-2020). Kigali: UNHCR. Available at: www.unhcr.org/rw/wp-content/uploads/sites/4/2017/02/ Economic-Inclusion-of-Refugees-in-R wanda-Final-Version.pdf

Munoz-Boudet, A. M., Petesch, P., and Turk, C. (2013) On norms and agency: conversations about gender equality with women and men in 20 countries. Washington, DC:The World Bank.

National Institute of Statistics of Rwanda, Ministry of Finance and Economic Planning/ Rwanda, Ministry of Health/Rwanda, and ICF International. (2015) Rwanda demographic and health survey 2014-15. Kigali, Rwanda: National Institute of Statistics of Rwanda, Ministry of Finance and Economic Planning/Rwanda, Ministry of Health/Rwanda, and ICF International.

Pavlish, C. (2005) Refugee women's health: collaborative inquiry with refugee women in Rwanda. Health Care for Women International 26(10): 880-896.

Pavlish, C. (2007) Narrative inquiry into life experiences of refugee women and men. International Nursing Review 54(1): 28-34.

Pavlish, C., and Ho,A. (2009) Pathway to social justice: research on human rights and genderbased violence in a Rwandan refugee camp. Advances in Nursing Science 32(2): 144-157.

Pavlish, C. L. P. (2004) Life stories of refugee women at Gihembe Refugee Camp in Byumba, Rwanda. Ph.D. Dissertation, University of Minnesota. 
Pulerwitz, J., Blum, R., Cislaghi, B., Costenbader, E., Harper, C., Heise, L., Kohli, A., and Lundgren, R. (2019) Proposing a conceptual framework to address social norms that influence adolescent sexual and reproductive health. Journal of Adolescent Health 64(4): S7-S9.

Requejo, J., Diaz, T., Park, L., Chou, D., Choudhury, A., and Guthold, R. (2020) Assessing coverage of interventions for reproductive, maternal, newborn, child, and adolescent health and nutrition. British Medical Journal 368: 16915.

Rulisa, S., Umuziranenge, I., Small, M., and van Roosmalen, J. (2015) Maternal near miss and mortality in a tertiary care hospital in Rwanda. BMC Pregnancy and Childbirth 15(1): 203.

Ruzibiza, R. (2020) 'They are a shame to the community. . ' stigma, school attendance, solitude and resilience among pregnant teenagers and teenage mothers in Mahama refugee camp, Rwanda. Global Public Health. DOI: 10.1080/17441692.2020.1751230

Sipsma, H. L., Falb, K. L., Willie, T., Bradley, E. H., Bienkowski, L., Meerdink, N., and Gupta, J. (2015) Violence against Congolese refugee women in Rwanda and mental health: a cross-sectional study using latent class analysis. BMJ Open 5(4): e006299.

Sommer, M., and Mmari, K. (2015) Addressing structural and environmental factors for adolescent sexual and reproductive health in low- and middle-income countries. American Journal of Public Health 105(10): 1973-1981.

Turner, S. (2016) What is a refugee camp? Explorations of the limits and effects of the camp. Journal of Refugee Studies 29(2): 139-148.

UNHCR. (n.d.) Information on refugees in Rwanda. UNHCR website. Available at: www. unhcr.org/rw/refugees

UNHCR. (2019) Rwanda country refugee response plan 2019-2020. Geneva: UNHCR.

United Nations High Commissioner for Refugees (UNHCR), Child Protection in Conflict Learning Network (CPC) and the Association of Volunteers in International ServiceRwanda (AVSI). (2014) Pilot study in Rwanda to develop evidence-based child protection/sexual and gender-based violence assessment tools. Geneva: UNHCR.

United Nations Secretary-General. (2015) Every woman every child: the global strategy for women's, children's and adolescents. Health 2016-2030.

Wako, E., Elliott, L., De Jesus, S., Zotti, M. E., Swahn, M. H., and Beltrami, J. (2015) Conflict, displacement, and IPV: findings from two Congolese refugee camps in Rwanda. Violence Against Women 21(9): 1087-1101.

WFP and UNHCR. (2014) WFP-UNHCR joint assessment mission Rwanda. Kigali: UNHCR and WFP.

Williams, T. P., Chopra, V., and Chikanya, S. R. (2018) 'It isn't that we're prostitutes': child protection and sexual exploitation of adolescent girls within and beyond refugee camps in Rwanda. Child Abuse \& Neglect 86: 158-166.

World Food Programme (WFP). (2018) Food and safety net assistance to refugee camp residents and returning Rwandan refugees. Standard Project Report 2018. Rome:WFP. 